\title{
Team Roles and Hierarchic System in Group Discussion
}

\author{
Manabu Fujimoto ${ }^{1}$
}

Published online: 23 September 2015

(C) Springer Science+Business Media Dordrecht 2015

\begin{abstract}
Conventional systems for classifying team roles refer only to the function criterion and two categories, task and social; in addition, roles and behaviors are unspecialized, a one-to-one correspondence being assumed between them. These theoretical problems have resulted in overly fragmented roles as well as oversimplified categories. Therefore, this article aims to reveal essential roles and a unified system to classify them. In order to elucidate the team roles essential for discussion, a questionnaire survey was administered for Study 1, with the result that just ten discussant-roles were identified. For Study 2, in order to verify a classification system for the discussantroles, participant groups were asked to discuss itineraries for an overnight group trip during the winter holiday. The results showed that a three-criterion model based on the deep roles is superior to the traditional model. In this hierarchical system, characteristic behaviors are expressed according to ten discussant-roles, which are divided into six categories, using a combination of three criteria. This system not only solves the theoretical issues but also contributes to improving members' discussion behaviors.
\end{abstract}

Keywords Discussant-roles - Three-criterion model - A system of team roles .

Discussion

\section{Introduction}

Work teams have been formed in many organizations (Devine et al. 1999; Ilgen 1999) in order to improve productivity and worker satisfaction (Banker et al. 1996; Cohen

\footnotetext{
$\triangle$ Manabu Fujimoto

fuzimoto@fc.ritsumei.ac.jp

1 Institute for Teaching and Learning, Ritsumeikan University, 56-1, Toujiinkitamachi, Kita-ku, Kyoto-shi, Kyoto-fu 603-8577, Japan
} 
and Ledford 1994). The roles within such teams promote team cohesion and responsibility (Mudrack and Farrell 1995) foster positive interdependence and individual accountability (Brush 1998) and stimulate members' awareness of the overall group performance and of each member's contribution (Strijbos et al. 2004).

For these reasons, roles are considered to be a fundamental element of teams (Hackman 1990). Indeed, many researchers have noted the importance of team roles (cf. Hackman 1987; McGrath 1984; Sundstrom et al. 1990). However, little has been said about the actual distribution of the roles in a team (Hare 2003).

In teams, group discussions are central to social activities. Miller (1978) claimed that groups should be perceived as systems in which individuals interact. Most studies on teams focus chiefly on emergent social activities among individuals, particularly the function of discussion (Pavitt 1994), rather than on the team itself (Homans 1961). Social interactions and group discussions do play an important function in overall group dynamics, and for that reason, the roles that members of a team play in such discussions are important. Therefore, in focusing on group discussions, this article identifies and categorizes functional discussant-roles, ultimately aiming to elucidate a system of team roles. Because such a system has not yet been fully explored, some theoretical defects have given rise to the following two problems.

\section{Theoretical Background of the Article}

\subsection{Problem of the Fragmentation of Roles}

The first problem stems from an excessive proliferation of roles in the literature. Previous studies dealing with the identification of team roles have focused mostly on two types of contributions: task and socioemotion (Hare 1994). The former has been concerned with "functional roles," as explicated by Benne and Sheats (1948). They identified 27 roles to describe members' functions in team discussions, and since that study, varying numbers of roles have been identified in different studies (Belbin 1993; Margerison and McCann 1990). Mumford et al. (2006) note that since Benne and Sheats researched the issue, about 120 team roles have been identified in the literature. However, these are fragmentary and inconsistent, the reason being that roles have been operationally defined according to single, concrete behaviors (Mudrack and Farrell 1995).

Roles have been conceptually defined as clusters of relationship- or goal-oriented behaviors (Belbin 1981, 1993; Forsyth 1990; Stewart et al. 2005), suggesting that the first problem is a gap between the conceptual definitions and the operational definitions. In reality, a series of behaviors may be expressed by the same person with a particular intention. Therefore, we should try to understand not individual behaviors but rather a person's series of behaviors, which reflect his or her role and intent.

One merit of role theory is that the subject's intent may be assumed as the background for a series of behaviors, thus facilitating prediction of his or her behaviors. However, recognizing roles by a single behavior has not only led to an excessive proliferation of roles but also made this concept worthless and obscured individual differences (Mumford et al. 2008). Arguing that personality and roles are linked, Newcomb and Charters (1950) therefore focuses attention on individual differences, which 
in role-acquisition are referred to as "role repertoire," an aspect similar to personality. Possessing broad role repertories enables members to adapt to various situations (Ginnett 1990; McIntyre and Salas 1995; Parker 1996). This role repertoire can be expressed as the frequency pattern of one's usual role-acquisition. That is, individuals shift into appropriate roles out of their own repertoire as a stable trait, depending on the current team activities.

In order to solve the problem of regarding a single behavior as a role, we need to identify only the necessary and sufficient roles that are the common factors behind observed behaviors in team activities. Thus, on principle, and in order to achieve a good interface with the conceptual definition, this research defines team roles operationally as the background factor for a series of related behaviors.

\subsection{Problem of Insufficient Classification Systems}

The second problem relates to the one-dimensional nature of classification criteria. Benne and Sheats (1948) grouped 27 roles into three broader categories: task roles, maintenance roles, and individual roles. Recently, Mumford et al. (2006) classified 10 unique roles into three broader categories: task category, social category, and boundaryspanning roles. As in these above instances, many studies on leadership behavior after the 1950s have consistently identified just two role categories: task and socioemotion (Bass 1981; Fisher et al. 1998). This two-factor structure has been empirically supported (Forsyth 1990; Hare 1974); however, a universally accepted taxonomy of team roles does not yet exist (Stewart et al. 2005).

A simple structure of two categories based solely on function is insufficient for classifying the various team roles. The structure is one-dimensional, as demonstrated by the fact that, for example, leadership roles and membership roles remain undifferentiated in this system. Even in the 1940s, Benne and Sheats (1948) noted that role studies have unduly emphasized leaders, and this overemphasis remains even today (e.g., Morgeson et al. 2010). Although Benne and Sheats added "individual roles" as membership roles, almost all of these roles were non-contributive and selfish.

\subsection{Covert Roles as an Extraneous Factor of Acquainting Team Roles}

Two questions logically arise, then: How many roles are there, and how are they classified? One concept that provides a clue to answering these questions is "covert roles." These roles relate to team roles from an emotionally contributive perspective (Hare 1994) and lie somewhere between personality and functional team roles. Covert roles are displayed when such emotions as frustration, resentment, latent uncertainty, elation, or discord manifest within a team (Mann 1967; Mitroff 1983). Each covert role is implicitly assigned to the member who displays the appropriate personality for it. Furthermore, the covert roles of each person are often not acknowledged among the members.

Moxnes (1999) suggested the theory of "deep roles," a well-organized system relating to covert roles and reflecting latent aptitudes in regard to team roles. He classified deep roles by combining three imperatives: evaluation, gender, and hierarchy. These 
imperatives are defined as biological or psychobiological elements long present in human societies.

The first imperative, evaluation, may be divided into good and bad. In group problem-solving, members are assessed according to the value of their contributions to the team or its activity. Therefore, the evaluation imperative should be regarded as a contribution criterion, in which roles are divided into Positive and Negative. The second imperative is gender. Shaver and Buhrmester (1983) argued that men are socialized to focus on social participation in groups and organizations, whereas women are socialized to focus on intimacy. This observation helps us realize that task and socioemotion are categories that correspond to gender, and they can be regarded as Task and Social in terms of a function criterion. The third imperative is hierarchy. Groups tend to give rise to hierarchical structures (Magee and Galinsky 2008; Wright 1994). The influential role and existence of central figures in groups have been repeatedly identified in the literature (Dirkx 1991). Because members' influence as based on their roles actually emerges as the hierarchy of organizations, the hierarchy imperative can be reconceived as an influence criterion with two categories: Superior and Subordinate. Thus, the imperatives that govern team roles correspond to the above three criteria of contribution, function, and influence.

\subsection{Identifying Categories of Discussant-Roles by Combining the Three Criteria}

Categories for classifying team roles properly are necessary for specifying and systematizing them. Such categories can be constructed by combining the three criteria. In terms of Positive-contributive roles, by combining the influence criterion with the functional criterion, we can classify contributive team roles into four categories: Initiative, Coordinative, Assertive, and Receptive.

Regarding the remaining Negative-contributive roles, Benne and Sheats (1948) listed eight individual roles that are Negative contributors. These roles can be divided into two categories according to what they do: some are harmful in terms of accomplishing tasks, such as "aggressor," "blocker," "dominator," and "evader and self-confessor"; and some hinder team activity, such as "help seeker," "recognition seeker," "playboy/girl," and "special-interest pleader." Thus, we can place the first four roles above into an Obstructive category wherein Subordinate is combined with Task-orientation, while the latter can be assigned to an Inactive category wherein Subordinate is combined with Social-orientation. Although the "dominator" in the former category fulfills some conditions of Superior roles, no other role does. An absence of Superior and Negative-contributive roles is natural because the main purpose of team work is to improve a current situation. The result might be a worse situation, but we do not aim to fail at tasks when we perform team work or to worsen people's moods. Therefore, in a team formed specifically for cooperative problem solving, Superior and Negative-contributive roles that attempt to thwart the team's purpose cannot exist.

Thus, there may be little need to introduce the Superior categories into Negativecontributive roles. We then have eight categories in combination with three imperatives, but a perusal of the literature suggests six categories of discussant-roles, as expressed in Table 1. 
Table 1 Role categories guided by three criteria

\begin{tabular}{llll}
\hline Criteria & & & Categories of roles \\
\hline Influence & Function & Contribution & \\
\hline Superior & Task & Positive & Initiative \\
& Social & Positive & Coordinative \\
Subordinate & Task & Positive & Assertive \\
& & Negative & Obstructive \\
& Social & Positive & Receptive \\
& & Negative & Inactive \\
\hline
\end{tabular}

\section{The Aims and Structure of the Article}

Exploring roles is fundamental to the study of teams. However, the fragmentation of identified roles as the first problem and the insufficiency of a classification system as the second problem have prohibited the progress of research into team roles. For development in this area, it is necessary to apply operational definitions of the roles to the conceptual ones; to establish a uniform system, including some concepts of the roles; and additionally, to develop a shared scale, which is needed to identify and measure the roles that people naturally take upon themselves.

Team members express behaviors depending on the roles they take on in team activities. This means that is should be possible to express the characteristic behaviors of these roles. Thus, Study 1 attempts to identify enough discussant-roles with this inductive approach to elucidate conceptually matched roles pertaining to the first problem.

Next, as mentioned above, team roles and their role-characteristic behaviors will be fitted into six categories as derived from the three criteria of contribution, function, and influence. Therefore, this article deals with four concepts which are in a hierarchical relationship: criteria, categories, roles, behaviors. Behaviors are expressed depending on roles; the roles are assigned to categories; and categories are derived according to the criteria. Accordingly, it is reasonable to think that these concepts are positioned sequentially in a four-layer structure, beginning with behaviors at the lowest level. Thus, Study 2 aims to elucidate a classification system of discussant-roles through verification of three relationships among four layers to solve the second problems pertaining to oversimplified classification.

This article includes an account of two studies. To obtain conceptually adapted codes for specifying discussant-roles actually acquired by the participants, a questionnaire survey was conducted for Study 1 concerning frequently expressed discussion behaviors. Next, one or more roles are derived from the contents of behaviors by a two-stage exploratory factor analyses (EFA). Then, a SEM (structural equation modelling) of each model of primary factors, which will be obtained from the first stage of an EFA, is verified by a confirmatory factor analysis (CFA).

For Study 2, participants were invited to group discussions for the purpose of collecting video data of observed role-acquisition behaviors. In the analysis stage, Analysis 1 verifies the relationships between acquired roles as the third layer and 
utterance behaviors as the fourth layer, as expressed in the discussions, using multiple regression analysis to address the first problem regarding the traditional one-to-one correspondence that has caused the fragmentation of roles. Analysis 2 verifies a SEM, which indicates each relationship between criteria, categories, and roles, corresponding to the first layer through the third layer by means of a CFA. If these two analyses confirm the relationships among the four layers, the hierarchical system for classifying discussant-roles will be demonstrated.

\section{Study 1: Identifying the Discussant-Roles and Role-Characteristic Behaviors}

Study 1 aims to obtain discussant-roles oriented toward a conceptual definition of roles as clusters of behaviors. To list the essential roles consistent with the conceptual definition, a questionnaire survey was used to identify the discussant-roles according to their characteristic behaviors from a self-description preliminary survey.

\subsection{Method}

\subsubsection{Preparation of Question Items}

A preliminary survey was conducted of 105 participants $^{1}$ (80 females, 25 males; average age $=21.46, S D=4.17$ ).

The aim was to distill "essential" group roles - that is, those acquired frequently by many of the participants. Thus, they were first asked to list freely up to three roles they had often played during past group discussions in order to discover the typical roles that discussants acquire most frequently. Then, they were asked to provide up to six characteristic behaviors for each role. This preliminary survey obtained 896 responses regarding frequent characteristic behaviors in group discussions.

Three research collaborators who were not privy to the study's details classified the 896 responses. In order to summarize similar responses, coding was repeated until consensus among the three coders was reached, resulting in 98 items.

\subsubsection{Participants and Process}

A main survey was then administered to 384 participants (197 females, 187 males; average age $=21.69, S D=1.46$ ). A questionnaire was distributed simultaneously to all participants, who were asked to recall and to assess their past behavior in group discussions concerning 98 items on an 11-point scale, where 10 means corresponds completely $(100 \%)$ and 0 means doesn't correspond at all $(0 \%)$.

\footnotetext{
1 Because participants in all the surveys conducted for all the studies presented in this article were Japanese undergraduates, the research and instruction were conducted in Japanese. For this article, a research collaborator, who is a native speaker of English and is familiar with both Japanese and psychology, checked whether question items and terms, such as roles and categories, are appropriate.
} 


\subsection{Results and Discussion}

First, an EFA was conducted using the maximum likelihood method and promax rotation. The highest positive load displayed at 0.300 or more and was made the standard. The scree test ${ }^{2}$ indicated four primary factors (PFs). The number of items was 42 items for PF 1, 21 items for PF 2, 19 items for PF 3, and 12 items for PF 4. Four items did not load to any of the factors.

In order to identify the concrete discussant-roles comprehensively, I conducted an additional EFA with the maximum likelihood method and promax rotation for the items loaded to each PF. In order to carefully select role-characteristic behaviors, the criteria were raised and the analysis repeated with items excluded that were less than 0.400 for each factor or 0.400 or more for multiple factors (Table 2). From the results, PF 1 was then divided into four factors: summarizer, speaker, critic, and obstructor. PF 2 was divided into two factors: balancer and listener. PF 3 was divided into two factors: spectator and inhibitor. Finally, PF 4 was divided into two factors: leader and moderator. In addition, whether each PF was subdivided sufficiently was tested by confirmatory factor analyses (CFA). ${ }^{3}$ In the results, all models showed good fit at some level. Moreover, the inter-factor correlation coefficients between factors in each factor model ranged from 0.592 to 0.668 , excluding obstructor.

First, regarding the four roles of PF 1, the former three, which are Task-oriented Positive contributive roles, direct the development of the discussion.The summarizer leads members with different views to agreement by resolving all opinions in a conclusion. The speaker expands the discussion by providing information, expressing his or her own opinion, and questioning aggressively. The critic specifies and refines the discussion by critically commenting on the contents of other members' statements. The remaining role of obstructer, which is a Subordinate, Task-oriented Negative contributive role, is unusual because it exerts a negative influence on the smooth progression of the discussion. The reason for the lower average value was that acquisition of such a negative role tends to be avoided in a team with the common purpose of problem solving (Moxnes 1999). However, an obstructor may emerge at any time within team activities. If perchance any member adopts this role, it has a profound negative effect on the team and its activities. Therefore, obstructor is never a negligible role. Because the CFA shows good fit for the assertive factors model, obstructor should be retained.

Second, the two roles of PF 2 are Social-oriented Positive contributive roles; these arise from listening to what other members have to say. Out of them, thebalancer forestalls any problems by focusing on the overall picture and contributes to creating a fair environment by listening equally to the opinions of all participants. On the other hand, the listeners function as the addressees of utterances and strongly orient their behavior to a speaker, responding with back-channeling, nodding, and repetition to encourage the speaker to continue (Fishman 1983). While both the balancer and

\footnotetext{
2 In the scree test, the eigenvalues for each factor are plotted; these constitute an incline, and the factors extracted are those between the incline of the curved line and the point where the line smooths out into a plane.

${ }^{3}$ If you would like to view the results of CFA, descriptive statistics, and interfactor correlations, please contact me http://www.psychommu.net/study/discussion/grup01.
} 
Table 2 Factor loading for primary factors

\begin{tabular}{|c|c|c|c|c|c|}
\hline No & Characteristic behaviors & Factor loadin & & & \\
\hline Prin & $\mathrm{y}$ factor 1 & Summarizer & Speaker & Critic & Obstructer \\
\hline 28 & $\begin{array}{l}\text { I organize the main points of } \\
\text { discussions or opinions }\end{array}$ & 0.735 & 0.164 & -0.067 & -0.057 \\
\hline 46 & I consolidate member opinions & 0.730 & -0.085 & 0.131 & 0.051 \\
\hline 47 & $\begin{array}{l}\text { I rephrase other members' opinions } \\
\text { to simplify meaning }\end{array}$ & 0.713 & -0.054 & 0.169 & -0.003 \\
\hline 29 & I present appropriate topics & 0.598 & 0.240 & -0.068 & 0.116 \\
\hline 15 & I actively state opinions and realizations & 0.011 & 0.743 & 0.104 & 0.078 \\
\hline 16 & $\begin{array}{l}\text { I speak to enable my opinions to be } \\
\text { understood }\end{array}$ & 0.173 & 0.716 & -0.049 & -0.051 \\
\hline 43 & I clearly state one's opinions & 0.123 & 0.636 & 0.151 & -0.076 \\
\hline 3 & I ask questions about unclarified issues & -0.095 & 0.487 & 0.257 & 0.043 \\
\hline 45 & $\begin{array}{l}\text { I question the reasons or basis for } \\
\text { other members' opinions }\end{array}$ & 0.185 & 0.147 & 0.617 & -0.058 \\
\hline 44 & $\begin{array}{l}\text { I state important opinions or } \\
\text { points others } \\
\text { are not aware of }\end{array}$ & 0.219 & 0.030 & 0.608 & -0.043 \\
\hline 40 & $\begin{array}{l}\text { I put forward counterarguments } \\
\text { or dissenting opinions }\end{array}$ & 0.011 & 0.160 & 0.577 & 0.106 \\
\hline 22 & $\begin{array}{l}\text { I point out deficiencies and } \\
\text { weak points in other } \\
\text { members' opinions }\end{array}$ & -0.032 & 0.207 & 0.538 & 0.106 \\
\hline 26 & I interrupt speech and change the topic & 0.028 & -0.062 & -0.072 & 0.750 \\
\hline 27 & $\begin{array}{l}\text { I lash out emotionally at other } \\
\text { members' utterances }\end{array}$ & -0.003 & 0.071 & 0.050 & 0.608 \\
\hline 42 & I act according to my own wishes & 0.028 & 0.012 & 0.149 & 0.482 \\
\hline Prin & y Factor 2 & Balancer & Listener & & \\
\hline 31 & I treat everyone equally & 0.731 & -0.025 & & \\
\hline 38 & I am attentive to my surroundings & 0.712 & 0.004 & & \\
\hline 13 & I listen equally to all opinions & 0.690 & 0.048 & & \\
\hline 24 & I listen calmly to all opinions & 0.539 & 0.114 & & \\
\hline 23 & $\begin{array}{l}\text { I properly understand all opinions and } \\
\text { thoughts }\end{array}$ & 0.520 & 0.112 & & \\
\hline 34 & $\begin{array}{l}\text { I back-channel in response to speakers' } \\
\text { opinions }\end{array}$ & -0.046 & 0.864 & & \\
\hline 20 & $\begin{array}{l}\text { I take care to adopt listener } \\
\text { behaviors such as } \\
\text { nodding when others speak }\end{array}$ & 0.077 & 0.665 & & \\
\hline 11 & I look at the speaker while listening & 0.008 & 0.634 & & \\
\hline 36 & $\begin{array}{l}\text { I listen to the opinion of other } \\
\text { members until } \\
\text { they have finished speaking }\end{array}$ & 0.368 & 0.417 & & \\
\hline
\end{tabular}


Table 2 continued

\begin{tabular}{|c|c|c|c|}
\hline \multirow{2}{*}{$\frac{\text { No }}{37}$} & \multirow{2}{*}{$\begin{array}{l}\text { Characteristic behaviors } \\
\begin{array}{l}\text { I make an effort to respond to } \\
\text { others' opinions }\end{array}\end{array}$} & \multicolumn{2}{|c|}{ Factor loadings } \\
\hline & & 0.256 & 0.415 \\
\hline \multicolumn{2}{|c|}{ Primary Factor 3} & Spectator & Inhibitor \\
\hline 9 & I listen to others but do not speak & 0.795 & 0.104 \\
\hline 1 & I quietly follow the discussion & 0.774 & -0.049 \\
\hline 2 & I do not state my opinion & 0.667 & 0.182 \\
\hline 10 & $\begin{array}{l}\text { I do not make unnecessary } \\
\text { comments }\end{array}$ & 0.658 & -0.097 \\
\hline 41 & I just listen & 0.627 & 0.220 \\
\hline 39 & I exclusively listen & 0.607 & 0.163 \\
\hline 7 & $\begin{array}{l}\text { I only make utterances when I } \\
\text { have a specific opinion }\end{array}$ & 0.511 & -0.094 \\
\hline 33 & I seek others with the same opinion & -0.262 & 0.776 \\
\hline 32 & $\begin{array}{l}\text { I am unable to speak for fear of } \\
\text { making mistakes } \\
\text { or being criticized }\end{array}$ & 0.167 & 0.760 \\
\hline 35 & I match other members' opinions & 0.198 & 0.537 \\
\hline 17 & I do not understand when to speak & 0.263 & 0.526 \\
\hline 21 & $\begin{array}{l}\text { I begin to speak once the } \\
\text { atmosphere has livened }\end{array}$ & 0.100 & 0.442 \\
\hline \multicolumn{2}{|c|}{ Primary Factor 4} & leader & Moderator \\
\hline 8 & I preside over the discussion & 0.972 & -0.096 \\
\hline 6 & I manage the discussion. & 0.883 & -0.006 \\
\hline 18 & I display leadership & 0.823 & 0.089 \\
\hline 30 & $\begin{array}{l}\text { I indicate my presence in the } \\
\text { discussion to others }\end{array}$ & 0.465 & 0.279 \\
\hline 25 & $\begin{array}{l}\text { I resolve arguments and } \\
\text { conflicting opinions }\end{array}$ & -0.036 & 0.644 \\
\hline 14 & $\begin{array}{l}\text { I judge the atmosphere of the } \\
\text { situation and adopt appropriate } \\
\text { behavior }\end{array}$ & -0.026 & 0.569 \\
\hline 5 & $\begin{array}{l}\text { I create an atmosphere that } \\
\text { encourages everyone to } \\
\text { speak }\end{array}$ & 0.211 & 0.558 \\
\hline 19 & $\begin{array}{l}\text { I skillfully control the climaxes } \\
\text { of the discussion }\end{array}$ & 0.333 & 0.540 \\
\hline 4 & $\begin{array}{l}\text { I pay attention to the pace and } \\
\text { time allocation } \\
\text { of the discussion }\end{array}$ & 0.072 & 0.503 \\
\hline 12 & $\begin{array}{l}\text { I ensure the smooth progression } \\
\text { of the discussion }\end{array}$ & 0.363 & 0.448 \\
\hline
\end{tabular}

The boldfaced numbers indicate factor loadings of more than 0.400 or less than -0.400 
listener relate chiefly to listening, the types of listening behaviors and their effects on the team are quite different.

Third, the two roles of PF 3, which are Subordinate Social-oriented Negative contributive roles, are not proactive in function; rather, they negatively influence the quality and quantity of discussion, as well as other participants' acts. Thus, inactive roles have a sufficient function in team activity. The spectator refrains from speaking by choice, instead observing the flow of discussion quietly; thus, this kind of behavior is thought to derive from the free will of the individual. In contrast, the inhibitor is observed in members who are somehow prevented from participating effectively because of personality traits or lack of ability. In sum, whereas the spectator lacks motivation, the inhibitor lacks confidence and skills.

Finally, the two roles of PF 4, which are Superior Positive contributive roles, are meta-roles that influence the whole group by governing the team and the discussion. These roles function by facilitating not only the discussion processes but also the group development processes (McGrath 1991). Out of them, theleader brings members toward task solution by exerting influence on the whole team and its activity, while themoderator contributes by maintaining a positive team atmosphere through resolving conflicts among members.

\section{Study 2: Empirical Examination of Team Roles in Group Discussions}

Study 2 consisted of an experimental observation so that participants could conduct a discussion in a natural state under given conditions. Then, the data from this observation were examined in order to identify criteria for classifying discussant-roles and the categories in combination with the criteria. In order to solve the first problem, the relationship between acquired roles and utterance behaviors in group discussions were verified. Then, to address the second problem, the goodness of fit of the threecriterion model was verified and compared with the traditional model based on Benne and Sheats (1948) and the four PFs model derived from the results in Study 1.

\subsection{Method}

\subsubsection{Participants}

For observation of natural discussion behaviors, a total of 95 individuals (23 males, 72 females $^{4}$; average age $=20.98, S D=1.14$ ) who did not have knowledge about discussant-roles participated in the experiment. These participants were acquainted with each other and independently formed a peer group with no obvious social hierarchy.

\footnotetext{
4 The findings of Study 2 might be affected because of a higher participation of females in the experiment compared to males. However, an unpaired $t$ test showed no difference between males and females in the frequency of codes of role acquisition and utterance behaviors.
} 


\subsubsection{Process}

All experiment participants were assembled in the questionnaire room for an explanation of the experiment. After they had given permission for being recorded, the participants were requested to sign a consent form. Next, the participants were requested individually to fill in an itinerary for a recent trip they had taken to give them practice in filling out an itinerary, the task they would be asked to accomplish later through group discussion.

Subsequently, the 95 participants were randomly separated into three groups and then asked to form teams of five people independently with whom they would not object to taking a vacation. Then, each team of participants was led to the discussion room, and they sat in chairs positioned at regular intervals at a round table. Next, they were given a general overview of the experiment. The team was asked to plan and create an itinerary for an overnight group trip during the winter holidays. This task was chosen as the result of a preliminary survey about what themes participants would usually discuss with peers. The reasons for this procedure were to motivate participants and to obtain data relating to their natural discussion behaviors. They were told that the trip plans and the discussion would be evaluated the following day by experiment collaborators using the video recording.

The planned discussion time was $30 \mathrm{~min}$, with a bell sounded upon commencement of the discussion, and at the 10- and 20-min marks. The participants were requested to raise their hands upon completion of the discussion, and the bell would sound if the discussion continued longer than $33 \mathrm{~min}$. The average discussion time was $30.94 \mathrm{~min}$ (SD 3.29).

\subsection{Pre-analytical Process}

\subsubsection{Coding Behaviors Corresponding to Discussant-Roles}

Two research collaborators who were unaware of the purpose of the study separately classified the behaviors corresponding to the discussant-roles expressed by each participant during the discussion into 10 codes corresponding to the discussant-roles identified in Study 1 (Table 3). The number of behavior expressions was counted by dividing the discussion time into 5-min sections, and identifying all the discussantroles played by the participants in each section. Of the 19 teams, 12 had a conversation length of seven sections, six had a length of six sections, and one team had a length of five sections. The counting results from the two collaborators showed a high Cohen's coefficient kappa of $89.15 \%$; therefore, the average values from both sets were adopted as data. The number of checks for all the sections was totaled, and the data for roleacquisition frequency were used for analysis.

\subsubsection{Coding Utterance Behaviors}

The utterance behaviors expressed by the participants in the group discussions were also analyzed. The total number of utterances, 18,669, was classified according to 20 


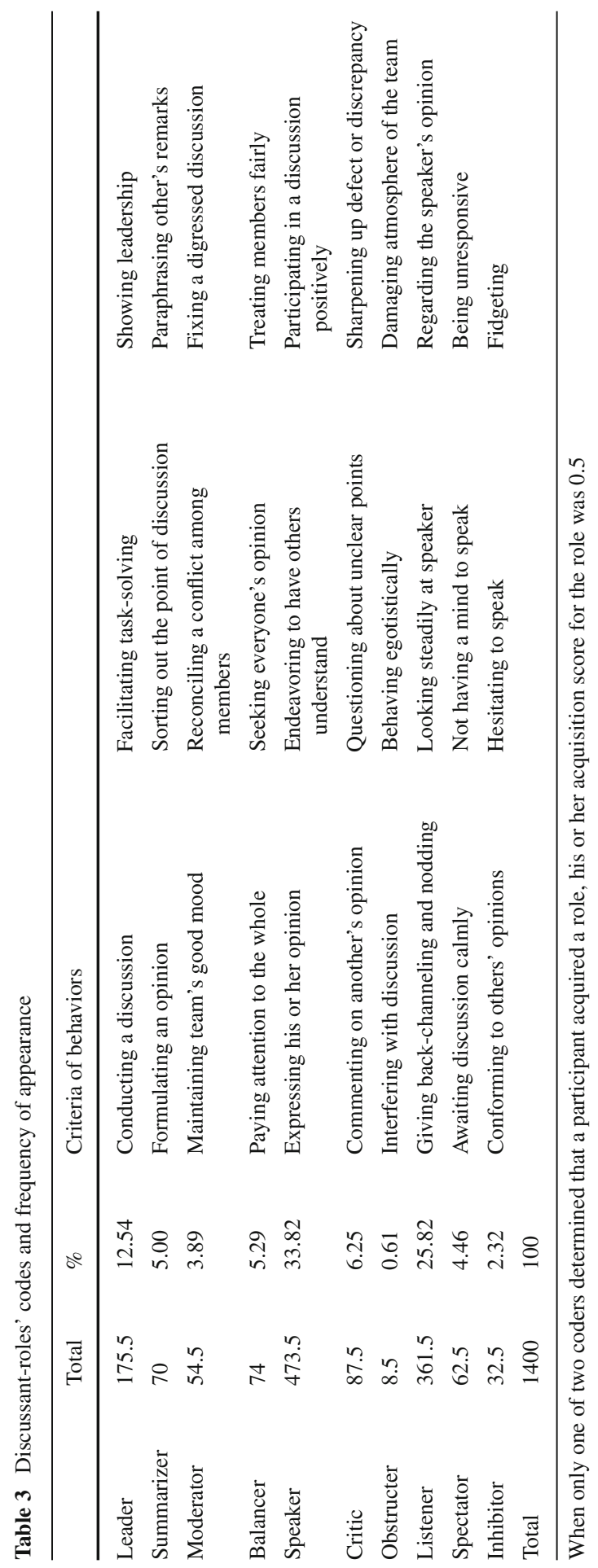


utterance codes through consultation among two research collaborators who did not participate in the coding of the discussant-roles (Table 4). These codes were based on Stiles (1992) Verbal Response Mode (VRM) and Fujimoto and Daibo (2007) narrative format codes.

\subsubsection{Calculating an Intragroup Ratio}

Subsequently, the role-acquisition frequency was converted to an intragroup ratio, which was derived by the total frequency of all categories for all members on the team. ${ }^{5}$ The intraclass correlation coefficient for the raw scores and the intragroup ratios were calculated in order to confirm that differences between teams were successfully controlled. Changes in the intraclass correlation coefficient owing to the intragroup ratio reflected a decrease of 0.023 , from an average of 0.075 ( $S D 0.162$ ) to 0.052 (SD 0.144 ), for the 10 role-acquisition frequency codes, and a decrease of 0.070 , from an average of 0.150 (SD 0.213) to 0.080 ( $S D$ 0.201), for the 20 utterance expression frequency codes. Even before processing, the intraclass correlation coefficient was significantly low, but conversion to an intragroup ratio further decreased the intraclass correlation coefficient. These results confirmed that differences between teams had been controlled with the intragroup ratio.

\subsection{Analysis 1: Utterance Expression Patterns Specific to Each Discussant-Role}

Study 1 has obviously identified that the ten discussant-roles have characteristic behaviors, thus partially solving the first problem regarding the fragmentation of roles. However, this finding is from a questionnaire survey. Therefore, Study 2 attempted to demonstrate the validity of the discussant-roles by verifying whether participants express the utterance patterns associated with roles actually acquired in group discussion. A multiple regression analysis was conducted using the stepwise method, with utterance expression frequency as the explanatory variable and role-acquisition frequency as the objective variable. Twenty indicators constituted too many candidates for the explanatory variable. Therefore, the following analyses were instead conducted by three clusters of codes: (1) those relevant to management utterance, (2) to active utterance and (3) to passive utterance.

First, a multiple regression analysis was conducted with management utterance codes as explanatory variables (upper third of Table 5). The roles which directly relate to these codes are leader, summarizer, moderator, and balancer. The leader showed a positive $\beta$ with discussion progression, digression avoidance, demanding utterance, and summarizing opinion. This role was the only one to show a significant relationship

\footnotetext{
5 Group data contain three sets of information on differences among groups, individuals, and codes. If in-group homogeneity (i.e., intraclass correlation coefficient) is high, group data that have information on differences among groups should be analyzed by HLM or multilevel SEM. The intragroup ratio conversion is a process that removes the information regarding the differences among the groups or reduces the intraclass correlation of group data. This procedure enables comparison of discussion participants outside the bounds of the groups.
} 


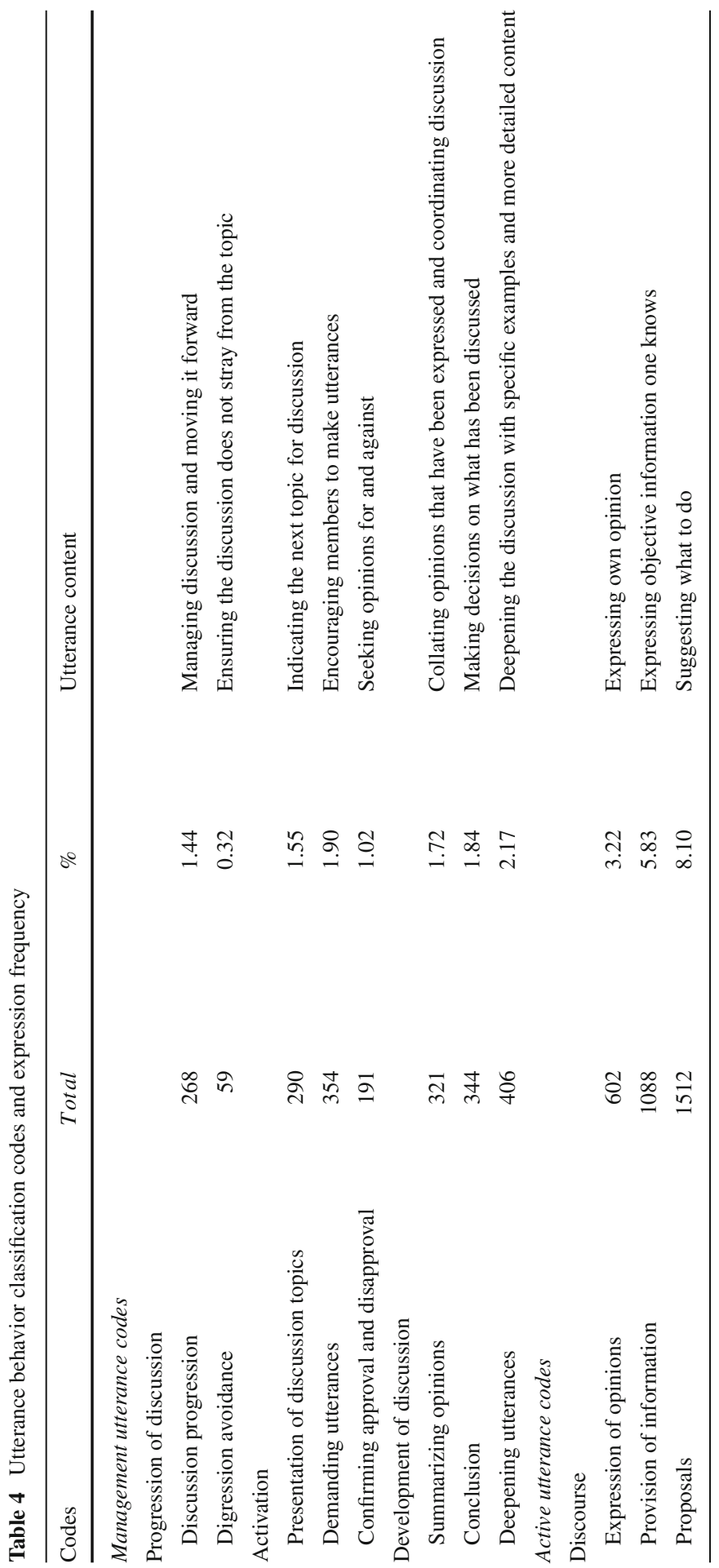




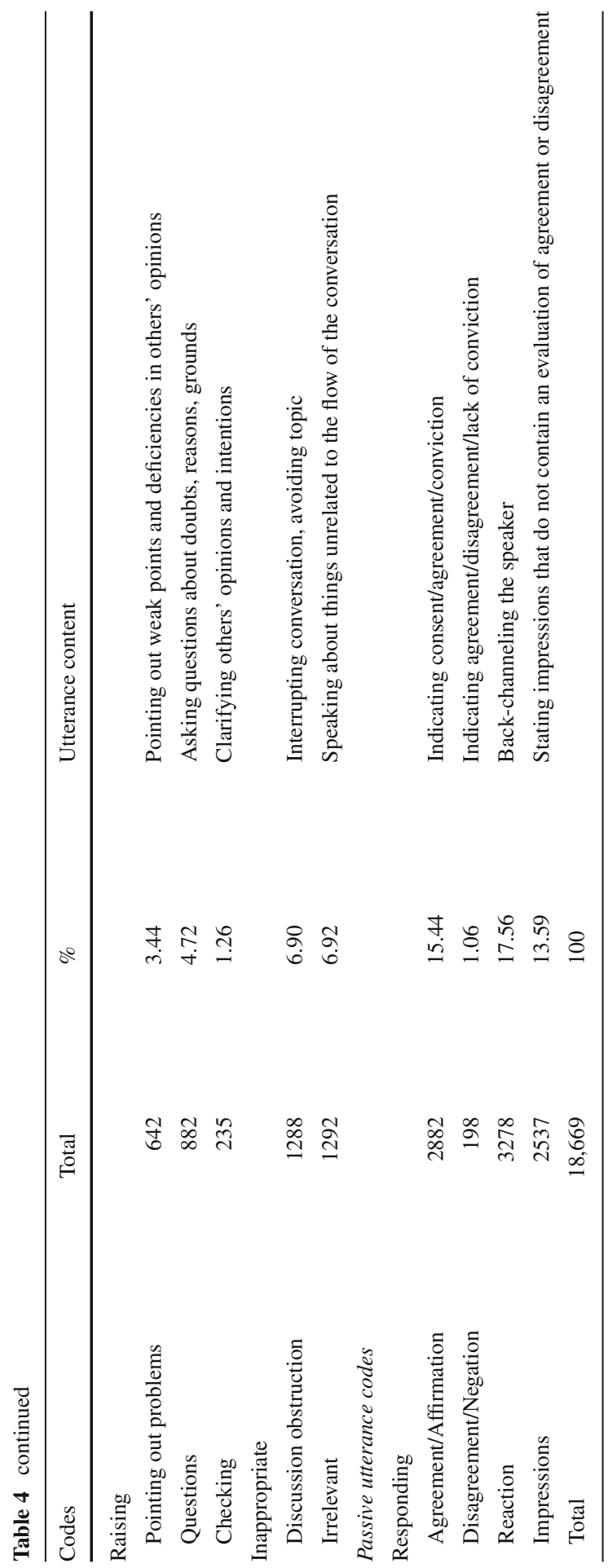


with discussion progression. Thus, the leader plays a central role in management by avoiding digression, demanding utterances from others, and consolidating opinions. The summarizer showed a positive $\beta$ with summarizing opinions and conclusions, attempting to collate opinions and formulate a conclusion for each topic. The moderator showed a positive $\beta$ with digression avoidance and summarizing opinions, as this role contributed to discussions by preventing digression and collating the multiple opinions expressed. The balancer showed a positive $\beta$ in the codes for eliciting utterances from others and in projecting support for or opposition to others' opinions. In addition, the speaker showed a positive $\beta$ with two codes of management utterance. This result suggests that this role introduces topics and also seeks utterances from others to activate the discussion.

Next, a multiple regression analysis was conducted with the active utterance codes as explanatory variables (middle third of Table 5). The roles that directly relate to these codes are the speaker, critic, and obstructer. The speaker showed a positive $\beta$ with expression of opinions, provision of information, and irrelevancy; indicating that this role is very active in group discussions. The critic showed a positive $\beta$ with pointing out problems and discussion obstruction. Even if this role rather spoils the smooth proceedings, it attempts to eliminate ambiguity during the discussion. The obstructer showed a strong positive $\beta$ with discussion obstruction, bearing out the definition of this role. In addition, the spectator and inhibitor showed a negative $\beta$ in these codes. These results suggest that inactive roles display no active participation in the discussion.

Finally, a multiple regression analysis was conducted with passive utterance codes as explanatory variables (lower third of Table 5). The roles are listener, spectator, and inhibitor. The listener showed a strong positive $\beta$ with reaction and agreement/affirmation, with disagreement/negation. Alternatively, thelistener showed a negative $\beta$ with impressions. These results emphasize the nature of the listener as an addressee. In addition, the speaker showed a strong positive $\beta$ with impressions, and the critic showed a strong positive $\beta$ with disagreement/negation. These roles not only contribute discursive utterances but also frequently react to others' utterances. However, they differ from the listener in that they disagree or make negating comments. Regarding the spectator, no positive relationship was indicated between this role and the reaction-type codes. While both the listener and spectator are passive roles, the spectator merely remains present in the situation and nothing more. The difference between the inhibitor and spectator is that the inhibitor did not show a negative $\beta$ with agreement/affirmation or reaction. Thus, while the spectator, who has no intention of participating, and the inhibitor, who hesitates to join the discussion or make a negative utterance, both avoid making utterances, the meaning behind their behaviors is profoundly different.

As observed above, the results were consistent with all the definitions of discussant-roles. The 10 discussant-roles were verified as having characteristic behaviors, which means that the first problem concerning the fragmentation of roles is resolved. The next section attempts to analysis the structure of these discussant-roles in order to solve the second problem regarding oversimple classification. 


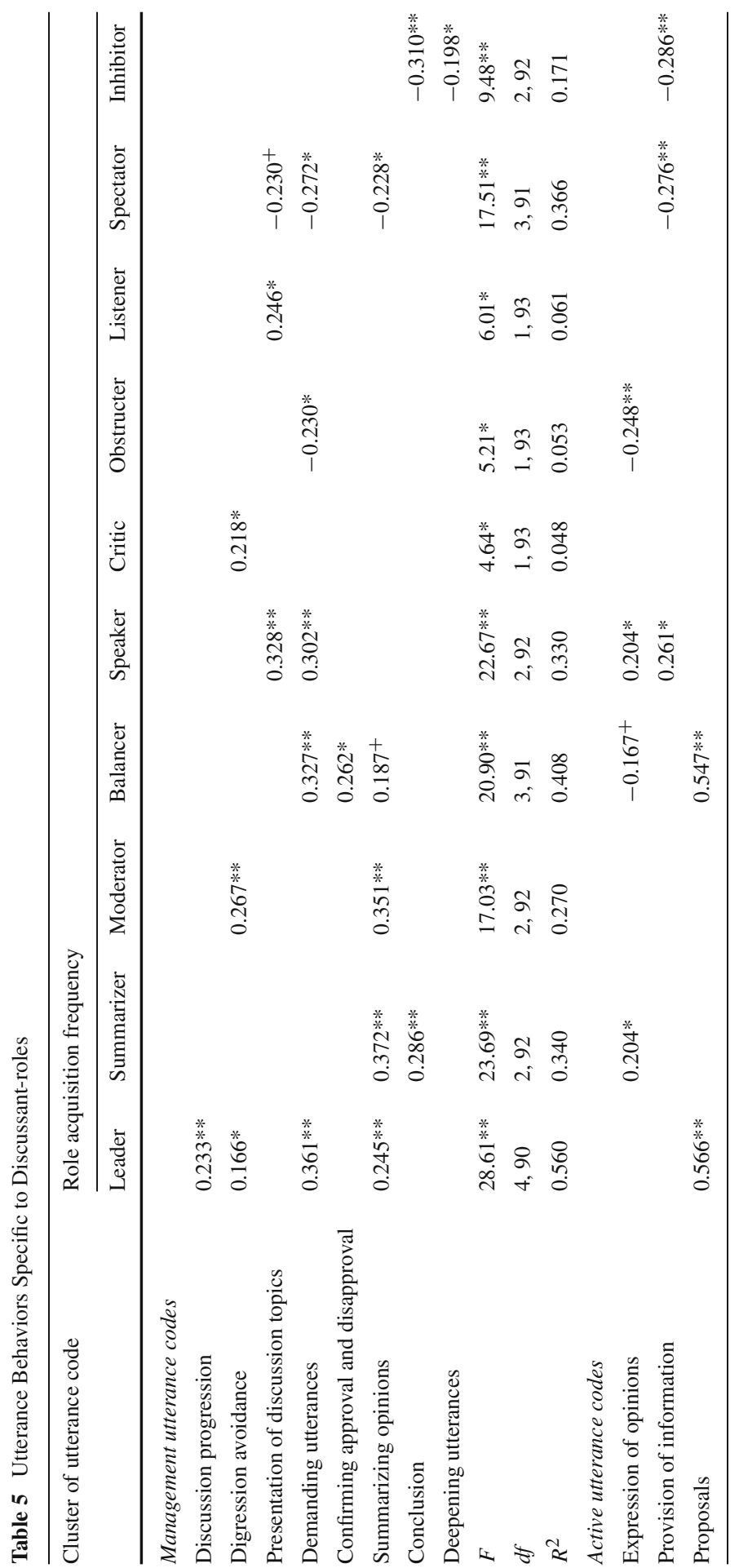




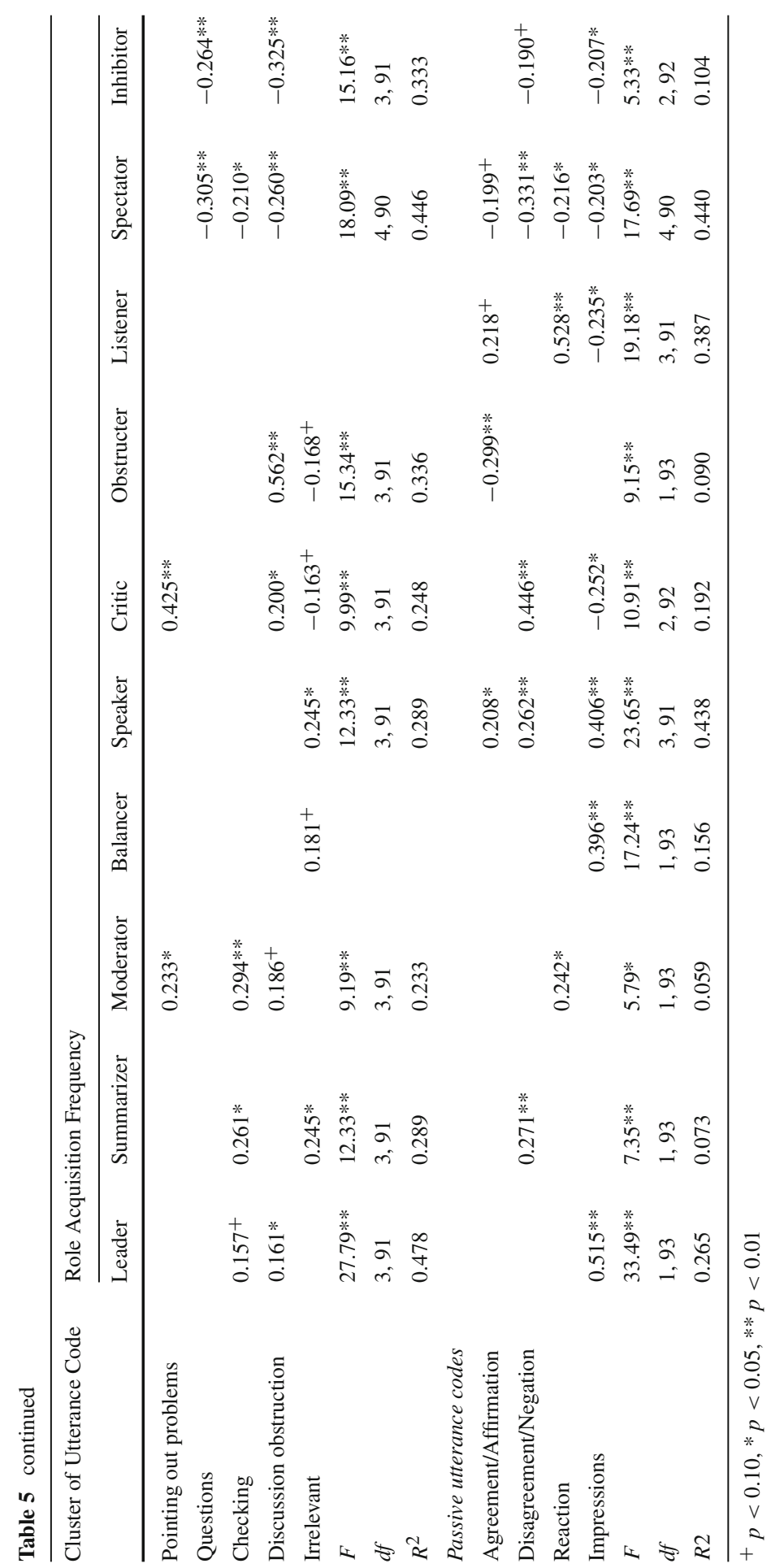




\subsection{Analysis 2: Specification of the Structure of Discussant-Roles}

Analysis 2 examined the hierarchical relationship between criteria and roles. A CFA was conducted to verify and compare the traditional model, based on Benne and Sheats (1948); the three-criterion model, based on deep roles; and the four PFs model based on the results in Study 1.

The traditional model has three latent variables: task category, including such Task-oriented Positive contributive roles as leader, summarizer, speaker, and critic; maintenance category, including such Social-oriented Positive contributive roles as moderator, balancer, and listener; and individual category, including the Negative contributive roles of obstructer, spectator, and inhibitor. The three-criterion model is a multiple structure consisting of latent variables that are separated according to three criteria. The lowest-order latent variables represent six categories (Table 1), and the observed variables are the acquisition frequency of 10 discussant-roles. The four PFs model has four latent variables based on Table 2 .

According to the results of the CFAs, the traditional model (Fig. 1; $G F I=0.793$, $C F I=0.705, R M S E A=0.184, A I C=179.579$ ) and the four PFs model (Fig. 3; $G F I=0.865, C F I=0.853, R M S E A=0.136, A I C=131.633)$ did not demonstrate good fit. In contrast, the three-criterion model showed good fit at some level (Fig. 2; $G F I=0.911, C F I=0.955, R M S E A=0.077, A I C=97.551)$. The goodness of fit of the three-criterion model improved more dramatically than that of the traditional model.

The above results demonstrated that the three-criterion model was superior to the traditional model and the four PFs model as a classification system for team roles in discussion. The traditional classification system, which divides task and social roles only by function criterion and lumps together all the Negative contributive roles, is unable to categorize complex team roles adequately. If a member acquires roles in compliance with covert expectations from other members, it may be a natural thing for team roles to reflect the structure of deep roles. The reason the four PFs model proved inadequate was that the four PFs in Study 1 resulted from three criteria that emerged in an uneven fashion as follows: the assertive and receptive categories correspond to a function criterion, the passive category corresponds to a contribution criterion, and the management category corresponds to an influence criterion. The results from the

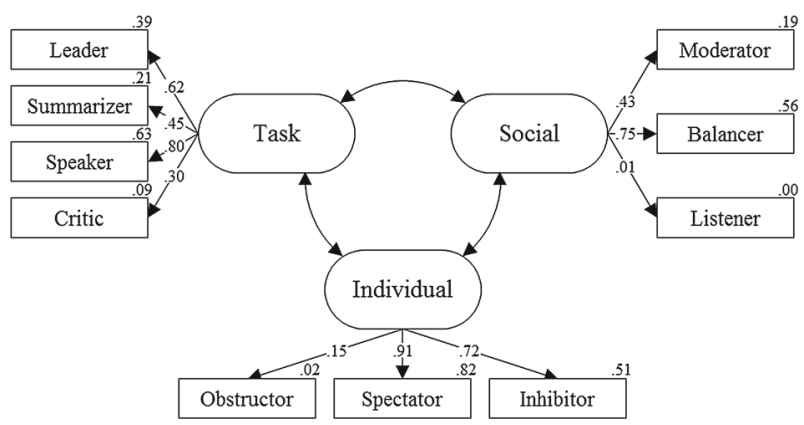

Fig. 1 Traditional Model Based on Benne and Sheats (1948). Note Error terms were omitted from model diagram to avoid complication. 


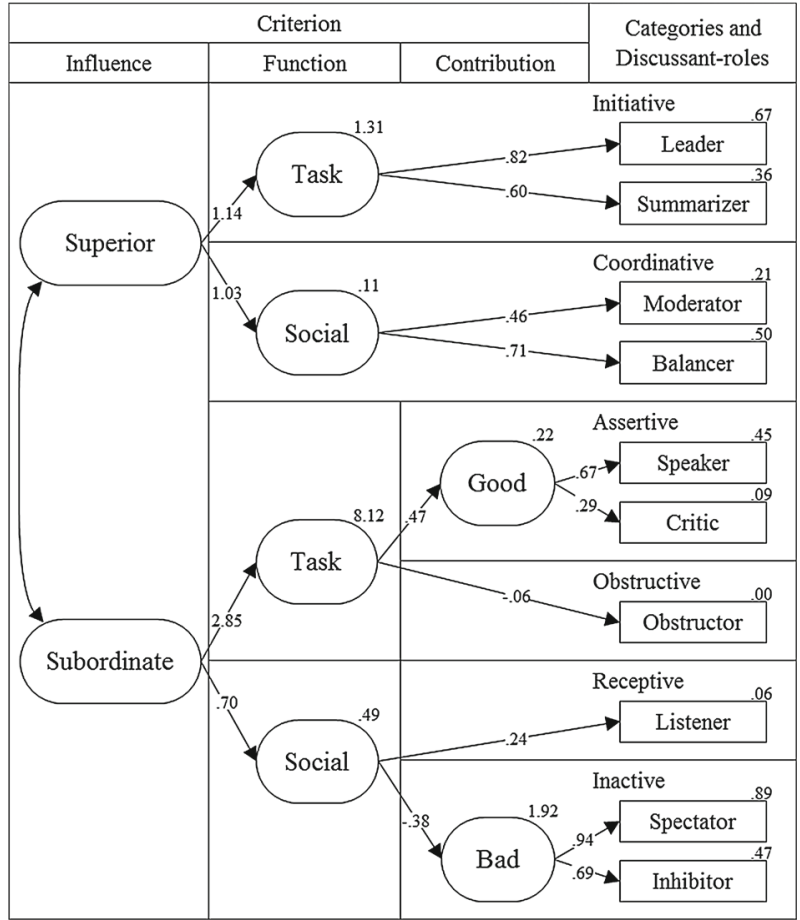

Fig. 2 Three-criterion model based on the structure of deep roles. Note Error terms were omitted from model diagram to avoid complication

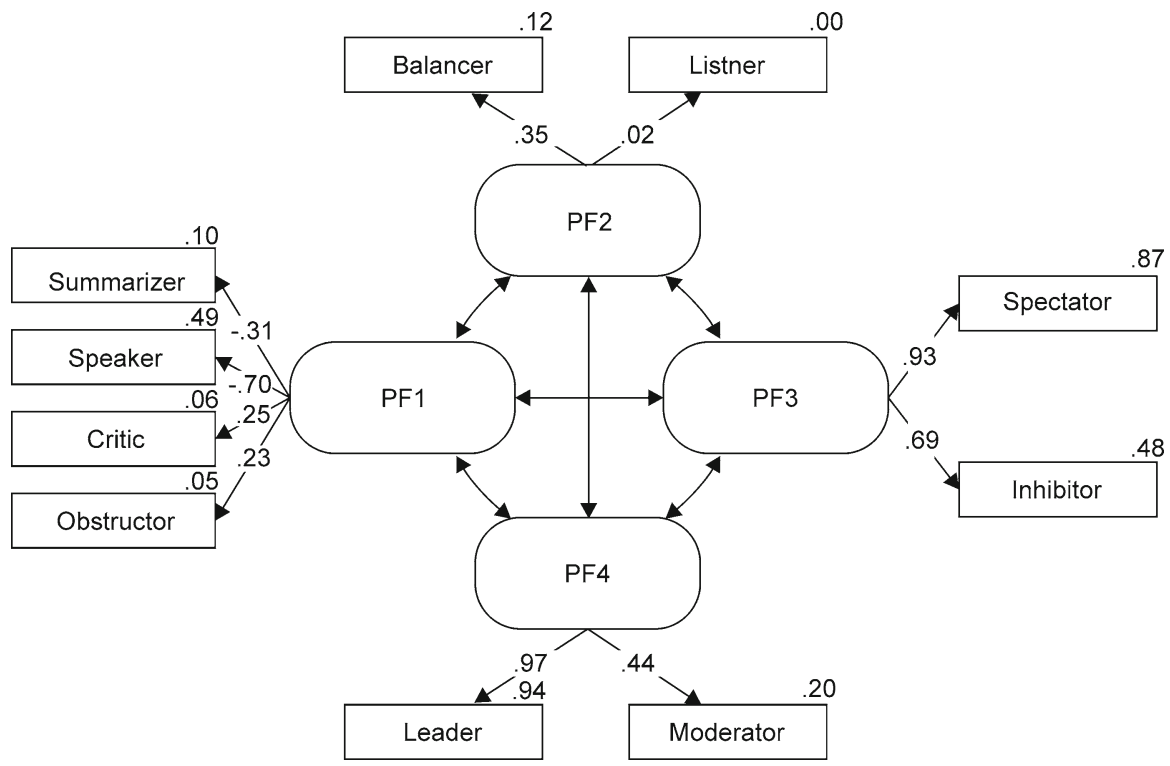

Fig. 3 Four PFs model based on the results in Study 1. Note Error terms were omitted from model diagram to avoid complication 
EFA in Study 1 will indicate that there are three criteria for classifying roles, and they take on significance only after they are combined.

\section{General Discussion}

This article has verified a role classification system that has a structure arising from 4 layers: 47 behaviors, 10 roles, 6 categories, and 3 criteria. The findings here are convincing for systematically understanding the concept of team roles, and they may also contribute to the practical applications discussed below.

\subsection{Theoretical Contributions of the Findings}

The theoretical findings extend the traditional theories and develop the concept of team roles through the following two points.

The first point concerns the relationship between roles and behaviors that was pointed out in the first problem. Existing roles have been operationally defined by concrete behaviors, thereby causing fragmentation of identified roles. However, in conceptual definitions, a series of behaviors is expressed, depending on the role which an individual acquired. In this article, discussant-roles are defined operationally as the factors that influence role-characteristic behaviors. Moreover, they showed a specific utterance pattern. Therefore, the first problem is fully resolved.

The second point concerns the relationship between three concepts: criteria, categories, and roles. Study 2 revealed three criteria in which the differences of influence and contribution are added into the classical framework, the functional categorization of task and socioemotion. Traditional theories of team roles have either been weighted toward leadership or have not discriminated between leadership and membership. The idea of role-sharing among members is now becoming the mainstream instead of the traditional leader-follower perspective. Thus, if we look at an influence criterion, it may appear that traditional classifications are going against the tide. For appreciating the diversity of roles, we need to innovate beyond the 65-year-old classification system, which is the current cognitive framework for team roles. Reaffirming team roles from the findings in this article helps us understand that it is reasonable to distinguish the leadership function of influencing others from the membership function of contributing to the task as a member.

Adding another criterion, contribution, teaches us that the words "function" and "contribution" do not always equate to a Positive-contribution. In practice, some members acquire Negative-contributive roles-such as obstructer, spectator, and inhibitor-in team activities. It is not that they merely contribute nothing; rather, they may negatively affect a team and its activities in various ways, such as causing conflict, lowering efficiency, boring other members, and leading to an inappropriate conclusion.

As shown above, identifying sufficient discussant-roles to elicit consistency in concepts of team roles as well as a classification system for them will help to develop this research field. This system shows the same construction in the classic works for group communication-namely, that the influence, function, and contribution crite- 
ria are common to the U-D, F-B, and P-N levels of SYMLOG, respectively (Bales and Cohen 1979; Keyton and Wall 1989). Thus, it is demonstrable that these findings extend and add value to existing work on team roles rather than denying their value.

\subsection{Practical Contributions of the Findings}

The 10 discussant-roles and their 47 characteristic behaviors (Table 2) could be transformed into an 11-point scale. The pattern for the scaled scores indicates the discussants' role repertoires. Therefore, this scale is labeled DRES, which is an acronym for Discussant-roles Repertoire Estimation Scale. Using this scale for a basis, the findings can have a practical application to achieving efficiency in a discussion. For example, if we want to learn how to behave in order to acquire a new role, we need to refer to the items for the factor that corresponds to the target role.

The DRES also provide useful criteria for distinguishing the different roles that show similar observable behaviors. In fact, either lack of motivation to participate (spectator) or lack of the skill needed to participate well (inhibitor) may be the reason that a member hardly speaks during a discussion. The scaled scores of these two roles offer information for determining what training or intervention should be offered to the member. Moreover, in taking a receptive role like balancer andistener, members can improve their performance by considering how to contribute to the group. Although the importance of listening has been pointed out indiscriminately (Goodwin 1986), the effects on others' utterance behaviors and discussion development differ between the balancer, who wishes to know everybody's opinion, and the listener, who attends with interest to whoever is speaking.

\subsection{Limitations and Future Research}

This article has some limitations. Study 1 adopted a questionnaire survey in order to identify discussant-roles. A common problem of this paradigm is using self-report. However, this study asked participants to recall their experience of role acquisition in discussion and to assess its frequency, which might be more objective than assessing the self per se. In addition, in Study 2, participants' role behaviors as actually expressed in discussion were assessed by third parties. Therefore, the 10 discussant-roles identified by the questionnaire survey were observed in real discussion, which is at least a means of verifying that their validity is adequate.

The discussion task adopted in Study 2 was cooperative rather than competitive, consisting of planning a group holiday. This approach prevented the participants from acquiring the obstructor role while activating a forward-looking discussion. Thus, as a team, the group might focus on cooperative aspects more than competitive aspects. Furthermore, Study 2 was carried out with extemporary groups. In practice, actual teams reiterate social interactions in the various scenes of continuous projects (McGrath et al. 2000). Thus, at this point, the findings of this article may be restricted in terms of generalization. Considering that many studies have been identifying team roles in the "real world" or by surveys only, this article, which presents the results of a laboratory study, may offer an additional perspective because it serves to clarify the nature of 
team roles in a group discussion by getting rid of extraneous variables, including the climate of an umbrella organization.

In relation to another difference between umbrella organizations and the context of this study, sex differences did not appear to exert an influence here. One reason is that biological gender differences do not have a direct influence on role-acquisition (Wheelan 1996). Gender differences, however, may be reflected in job classes and job types in umbrella organizations, which may indirectly influence role-acquisition.

Among other problems, this article focused on the roles acquired in group discussions, which are the central form of social activities in teams. However, when put into perspective with overall team activities, other types of team roles (e.g., boundaryspanning roles; Mumford et al. 2006) would need to be considered in further research. Moreover, the participants in Study 2 were peers whose social status was equal, although there was more or less difference in sociometric status. It is necessary to verify differences between peer teams and those with gaps in experience, ability, and public position.

This article has identified and offered a uniform system of discussant-roles. Future research should investigate how to divide and share roles among members and how, once acquired, these roles vary during a discussion.

Acknowledgments This work was supported by JSPS KAKENHI Grant Numbers 20730414, 22730495.

\section{References}

Bales RF, Cohen SP (1979) SYMLOG: a system for the multiple level observation of groups. Free Press, New York

Banker RD, Field JM, Schroeder RG, Sinha KK (1996) Impact of work teams on manufacturing performance: a longitudinal field study. Acad Manag J 39:867-890

Bass BM (1981) Stogdill's handbook of leadership: a survey of theory and research, rev edn. Free Press, New York

Belbin RM (1981) Management teams: Why they succeed or fail. Butterworth-Heinemann, Oxford

Belbin RM (1993) Team roles at work: a strategy for human resource management. Butterworth-Heinemann, Oxford

Benne KD, Sheats P (1948) Functional roles of group members. J Soc Issues 4:41-49

Brush TA (1998) embedding cooperative learning into the design of integrated learning systems: rationale and guidelines. ETRD Educ Technol Res Dev 46:5-18

Cohen SG, Ledford GE (1994) The effectiveness of self-managing teams: a quasi-experiment. Hum Relat 47:13-43

Devine DJ, Clayton LD, Philips JL, Dunford BB, Melner SB (1999) Teams in organizations: Prevalence, characteristics, and effectiveness. Small Gr Res 30:678-711

Dirkx JM (1991) Understanding group transformation through the focal person concept. In: Boyd RD (ed) Personal transformation in small groups: a Jungian perspective. Routledge, London, pp 65-96

Fisher SG, Hunter TA, MacRosson WDK (1998) The structure of Belbin's team roles. J Occup Organ Psychol 71:283-388

Fishman P (1983) Interaction: the work women do. In: Thorne B, Kramarae C, Henley N (eds) Language, gender and society. Newbury House, Rowley, pp 89-102

Forsyth DR (1990) Group dynamics, 2nd edn. Brooks/Cole, Pacific Grove

Fujimoto M, Daibo I (2007) Participants' predication patterns in small group communications (in Japanese). Jpn J Soc Psychol 23:23-32

Ginnett RC (1990) Airline cockpit crew. In: Hackman JR (ed) Groups that work (and those that don't): creating conditions for effective teamwork. Jossey-Bass, San Francisco, pp 427-448

Goodwin C (1986) Between and within: alternative treatments of continuers and assessments. Hum Stud 9:205-217 
Hackman JR (1987) The design of work teams. In: Lorsch JW (ed) Handbook of organizational behaviour. Prentice-Hall, Englewood Cliffs, pp 315-342

Hackman JR (ed) (1990) Groups that work (and those that don't): creating conditions for effective teamwork. Jossey-Bass, San Francisco

Hare AP (1974) Handbook of small group research, 2nd edn. Free Press, New York

Hare AP (1994) Types of roles in small groups: a bit of history and a current perspective. Small Gr Res 25:433-448

Hare AP (2003) Roles, relationships, and groups in organizations: some conclusions and recommendations. Small Gr Res 34:123-154

Homans GC (1961) Social behaviour: its elementary forms. Harcourt Brace Jovanovich, New York

Ilgen DR (1999) Teams embedded in organizations. Am Psychol 54:129-139

Keyton J, Wall VD (1989) SYMLOG: theory and method for measuring group and organizational communication. Manage Commun Quart 2:544-567

Magee JC, Galinsky AD (2008) Social hierarchy: the self-reinforcing nature of power and status. Acad Manage Ann 2:351-398

Mann RD (1967) Interpersonal styles and group development. Wiley, New York

Margerison C, McCann D (1990) Team management. W. H. Allen, London

McGrath JE (1984) Groups: interaction and performance. Prentice-Hall, Englewood Cliffs

McGrath JE (1991) Time, interaction, and performance (TIP): a theory of groups. Small Gr Res 22:147-174

McGrath JE, Arrow H, Berdahl JL (2000) The study of groups: past, present, and future. Pers Soc Psychol Rev 4:95-105

McIntyre RM, Salas E (1995) Measuring and managing for team performance: emerging principles from complex environments. In: Guzzo RA, Salas E (eds) Team effectiveness and decision making in organizations. Jossey-Bass, San Francisco, pp 9-45

Miller JG (1978) Living systems. McGraw-Hill, New York

Mitroff II (1983) Beyond experimentation: new methods for a new age. In: Seidman E (ed) Handbook of social intervention. Sage, Beverly Hills, pp 163-177

Morgeson FP, DeRue DS, Karam EP (2010) Leadership in teams: a functional approach to understanding leadership structures and processes. J Manage 36:5-39

Moxnes P (1999) Understanding roles: a psychodynamic model for role differentiation in groups. Group Dyn Theor Res 3:99-113

Mudrack PE, Farrell GM (1995) An examination of functional roles behaviour and its consequences for individuals in group settings. Small Gr Res 26:542-571

Mumford TV, Campion MA, Morgeson FP (2006) Situational judgment in work teams: a team role typology. In: Weekley JA, Ployhart RE (eds) Situational judgment tests: theory, measurement, and application. Erlbaum, Mahwah, pp 319-343

Mumford TV, Van Iddekinge CH, Morgeson FP, Campion MA (2008) The team role test: development and validation of a team role knowledge situational judgment test. J Appl Psychol 93:250-267

Newcomb TM, Charters WW Jr (1950) Social Psychol. Dryden Press, New York

Parker GM (1996) Team players and teamwork: the new competitive business strategy. Jossey-Bass, San Francisco

Pavitt C (1994) Theoretical commitments presupposed by functional approaches to group discussion. Small Gr Res 25:520-541

Shaver P, Buhrmester D (1983) Loneliness, sex-role orientation, and group life: a social needs perspective. In: Paulus P (ed) Basic group processes. Springer, New York, pp 259-288

Stewart GL, Fulmer IS, Barrick MR (2005) An exploration of member roles as a multilevel linking mechanism for individual traits and team outcomes. Pers Psychol 58:343-365

Stiles WB (1992) Describing talk: a taxonomy of verbal response modes. Sage, Newbury Park

Strijbos JW, Martens RL, Jochems WMG, Broers NJ (2004) The effect of functional roles on group efficiency: using multilevel modeling and content analysis to investigate computer-supported collaboration in small groups. Small Gr Res 35:195-229

Sundstrom E, De Meuse KP, Futrell D (1990) Work teams. Am Psychol 45:120-133

Wheelan S (1996) Effects of gender composition and group status differences on members' perceptions of group developmental patterns, effectiveness, and productivity. Sex Roles 34:665-686

Wright R (1994) The moral animal: evolutionary psychology and everyday life. Vintage Books, New York 